\title{
“All the places I've been to [in the tropics] are not really a special place": Investigating Children's Place Attachments through Collage and Stories
}

\author{
Tamara Brooks \& Reesa Sorin
}

James Cook University

\begin{abstract}
:
At the end of his book, 'Last Child in the Woods', Louv (2005, cited in Kellert, Heerwagen \& Mador, 2008, p.154) stated "it is evident that we are at a turning point in history where opportunities for children to explore the natural world, until recently taken for granted, must now be intentionally created". This statement was intended to communicate to the general public a disturbing reality - the growing disconnect between children and their local, natural environments. Sorin (2004) explains that children, particularly young children do not always have the words to describe what they see think or feel. Collage, an arts-based methodology has been found to reflect the ways in which our worlds are experienced (Butler-Kisber \& Poldma, 2009). This paper explores a researcher's investigation of young children's (7-9 years) 'special places'- better known as place attachments, using a qualitative, arts-based methodology. Methods of data collection and analysis will be discussed, as well as results that highlight the potential of the Arts to be used as research tools.
\end{abstract}

\footnotetext{
ustralia holds some of the most diverse and vulnerable ecosystems in the world, ranging from the marine, coral reefs, to the arid and semi-arid outback, to tropical rainforests (Westoby, 1993). The far north Queensland region of Australia is well known for its environmental treasures, specifically its two World Heritage sites: the Daintree Rainforest and the Great Barrier Reef. These environments require preservation, which the United Nations aims to achieve thorough implementation of the Decade of Education for Sustainable Development (2005-2014). The goals of the decade are dedicated to minimising irreversible human impacts on environments by educating people about how to live sustainable lifestyles (United Nations Education, Scientific and Cultural Organisation, 2009).
}

Environmental awareness and pro-environmental attitudes are thought to be the product of direct experiences with natural environments (Ewert, Place \& Sibthorp, 2005). "What is important is that children have an opportunity to bond with the natural world, to learn to love it and feel comfortable in it, before being asked to heal its wounds" (Sobel, 1996, p.10). Klassen (2010) notes it is important children are allowed to build a connection with the outdoors because if this connection with nature isn't encouraged and established, then it is feared the future generation may not deem the protection of the environment a necessary cause.

Louv (2005, cited in Kellert, Heerwagen, \& Mador, 2008, p.154) stated in his book 'Last Child in the Woods', "it is evident that we are at a turning point in history where opportunities for children to explore the natural world, until recently taken for granted, must now be intentionally created”. This statement was intended to communicate to the public a 
growing disconnect between children and their local, natural environments. This disconnect between child and environment has been labelled with many terms, including Wilson's (1984) 'biophobia', Pyle's (1993) 'extinction of experience' and Louv’s $(2005,2008)$ 'nature deficit disorder'. Research indicates the cause of this growing divide is denied opportunities for children to play in the natural environment as their predecessors had, with outdoor play declining by 50 percent in the last fifteen years (Hofferth, 2001, cited in Blizard \& Schuster, 2007). It seems important then, that efforts are implemented to reconnect children with their local environments.

Place attachment refers to a "person-place bond that evolves from specifiable conditions of place and characteristics of people” (Shumaker \& Taylor, 1983, cited in Steadman, 2003, p.672). Factors previous studies have identified as impacting on the formation of place attachments include: direct experiences with nature (Barraza, 1999; Ewert, Place \& Sibthorp, 2005; Wilson, 1997); familial role models (Chawla, 2007); stories attached to place (Blizard \& Schuster, 2007); and the physical affordances assigned to place (Steadman, 2003).

Ascertaining the places to which children feel attached can be a difficult process because as Sorin (2004) explains, children, particularly young children do not always have the words to describe what they see, think or feel. This paper outlines the 'special places' of childhood, otherwise known as place attachments, of a small group of children located in Far North Queensland. The researcher's methods of data collection and analysis will be discussed, as well as findings that highlight not only the place attachments of these children, but also the value of the Arts as a research tool.

\section{Research Background and Methodology:}

The research question of this study "What evidence of place attachments do young children represent using the Arts (collage/ stories)" was formulated based on a curiosity for implementation of Arts-based methodologies as research tools.

According to Huss \& Cwikel (2005) arts-based methods can involve using the arts as a method, subject, form of analysis or all of the above. The value that the Arts may have over traditionally used forms of written and verbally collected data is highlighted by Vygotsky (1971, cited in Alerby, 2000), who argues that art is closely related to thinking and can be thought of as an advanced way of thinking. Taking this into consideration, the Arts may be a valuable representational and meaning-making tool for children to demonstrate thought processes sometimes not communicable by words.

The art form implemented in this study was collage, a visual art technique that involves using images and materials, and gluing them to a flat surface to represent an idea or phenomena. Collage has been found to reflect the ways in which our world is experienced and to date has been utilised in research inquiry as "a reflective process, as a form of elicitation, and as a way of conceptualising ideas” (Butler-Kisber \& Poldma, 2009, p.2).

Fifteen children from a composite grade 2/3 class in an Independent school in Far North Queensland participated in the collage-making activity. Children were instructed to visualise and create a collage representation of their 'special place'. There were no discussions pertaining to the meaning of 'special place' in case this would influence children's artworks. Completion of the collage took place over three one-hour sessions, with the first hour used to visualise and construct a draft of the collage and a list of the materials needed to do so; and the final two set aside for the creation of the collage. 
Once collages were finished, storytelling, another art form, was employed to inform and enrich the data (Wright, 2008). It was noted that the visual alone may not communicate the child's full meaning, so storytelling was used to assist in enhancing children's expressions and the researchers' understanding of their ideas (Sorin \& Gordon, 2009). Anning \& Ring (2004) note that children's creativity is syncretistic, meaning the individual arts have yet to be separated and specialised; therefore children are likely to draw pictures and tell a story at the same time. Children were asked to share a story explaining what made their special place 'special'.

Completed collages, with their accompanying stories, were collected at the end of the sessions and subjected to a preliminary analysis, using a technique known as quantitative content analysis. Rose (2007) describes quantitative content analysis as counting the frequency of particular visual elements within a sample of images and then analysing those frequencies. This process entailed viewing the collages and noting the presence or absence of specific categories such as people, buildings and trees. Recurring categories were identified as possible influences in the formation of the child's place attachment.

An interview guide was created based on findings from this initial examination. Questions focused on ascertaining the physical, social, and emotional attributes that attracted the child to their special place. Sample questions include: Is your place special when you are alone or with others? Is your special place indoors or outdoors? Why? Is your special place close to home or far away? Why? How do you feel when you are in your special place?

Six children were purposively selected to participate in semi-structured interviews. These children were identified as "information-rich cases whose study would illuminate the questions under study” (Patton, 2002, p.230). Interviews with the children were spread over two days, taking approximately 15-20 minutes each. Children aged 4-8 years are in a stage of 'intuitive thought', categorised by a short attention span, which can impact on the quality of interview responses (Borgers, Hox, \& Leeuw, 2000). Therefore, it was felt that a shorter interview would be most appropriate. Preferred times and settings for the interviews were negotiated with the classroom teacher and the interview process was taped and transcribed.

Data from interviews and the stories were analysed using a grounded theory technique known as 'open-coding'. Open-coding involves the researcher in constructing qualitative codes from the data (Charmaz, 2006, cited in Black, 2009). Through immersion in the data common themes were identified and interpreted by the researchers as indicative of the key characteristics children afforded to their constructions of their special places.

By combining two data analysis techniques - content analysis and open-coding triangulation was achieved. By using triangulation the credibility of the data was increased and it seems as though a more holistic understanding of the child's place attachments was received. The data findings are discussed below.

\section{Findings:}

The findings from this study were initially separated into two sections: one indicative of the quantitative content analysis applied to the collages; and the other indicative of the qualitative open-coding of interview transcripts and stories. Quantitative content analysis of the children's collages revealed the presence of three key elements: natural elements (e.g. trees, 
water, animals), human-made elements (houses, play apparatus, gaming devices), and social elements (interactions with people).

In total 12 of 15 collages included some sort of natural element, such as the sun, clouds, animals, trees, weather elements, water, mountains and fruit. The sun was the natural element most frequently portrayed in children's collages, with 8 of the 15 participants including this element. Clouds, animals and trees were depicted in 6 collages each, with weather elements such as snow and rain included in 5 collages. Two collages included water, while mountain and fruit were each included in one collage.

Human-made elements including houses, cars, buildings and skyscrapers, playground equipment, household items, fences, display cases, garages and televisions were present in 14 of the 15 collages. Houses were the human-made element featured most often, with 6 collages including this element. Buildings and skyscrapers were depicted in 5 collages, followed by cars, household items (chairs, cupboards) and playground equipment, which were each presented in three collages. Human-made elements such as fences, display cases, garages and televisions were featured in one collage each.

One third (5 of 15) of the children's collages featured a social element, indicated by the presence of more than one person in the child's collage. Places featuring the social element were in two distinct settings: public domains and home locations. Three of the five collages were socially located in public domains, such as Dreamworld (theme park), Sci-tech (government educational initiative) and Gecko's (a local, indoor playground). The remaining two collages, including a social element were set in the child's home and featured representations of their family unit.

Open-coding of the children's stories and interview revealed six key categories, thought to impact on the formation of a child's place attachment. These categories were: physical location, physical features, social interactions, activity affordances, time, and positive feelings.

Children's 'special places' were found to be physically located in local, national or international settings; as well as either indoors or outdoors. The physical location was thought to be an influential factor because many children cited reasons such as "they only go there once a year", as contributing to the "specialness" of the place.

Two types of physical features were identified as being present in the children's place attachment stories and interviews: human-made and natural features. In children's verbal and written descriptions of their special place, human-made features often dominated natural ones, particularly in reference to gaming consoles (X360, Wii and DS). As one child's story states: "I like my home because I can play Xbox 360 and Wii and DS" (Figure 1). 


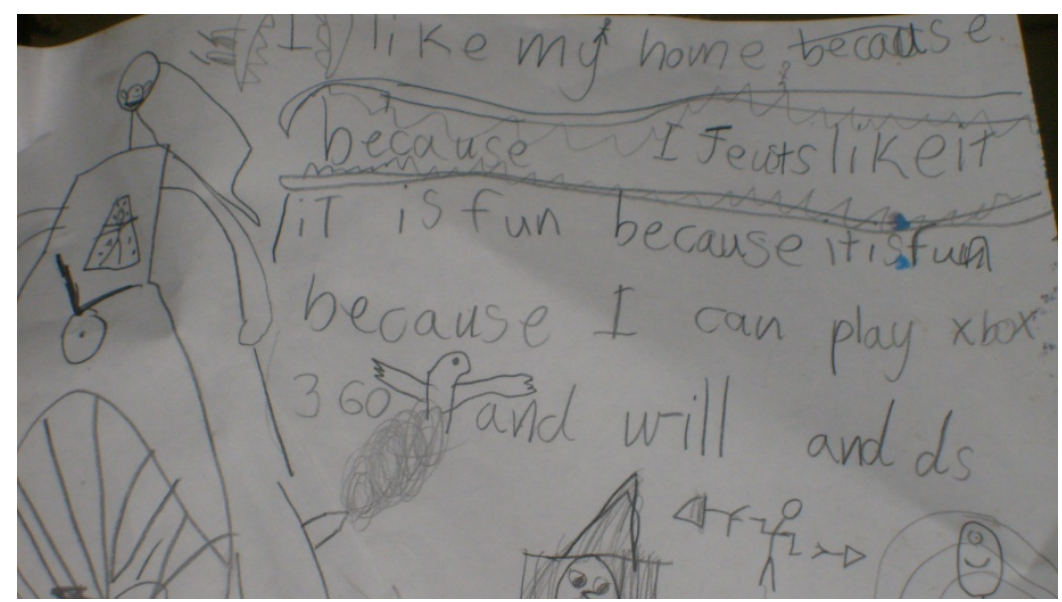

Figure 1

Social interactions were another category frequently mentioned in children's recounts of their 'special place'. Family and friends were often cited as being present in the child's special place and even identified as the main contributing factor to the 'specialness' of the place, as one young boy wrote "[This is] my annoying sister, my cute brother Luke, my dad and mum. This is why it is special” (Figure 2).

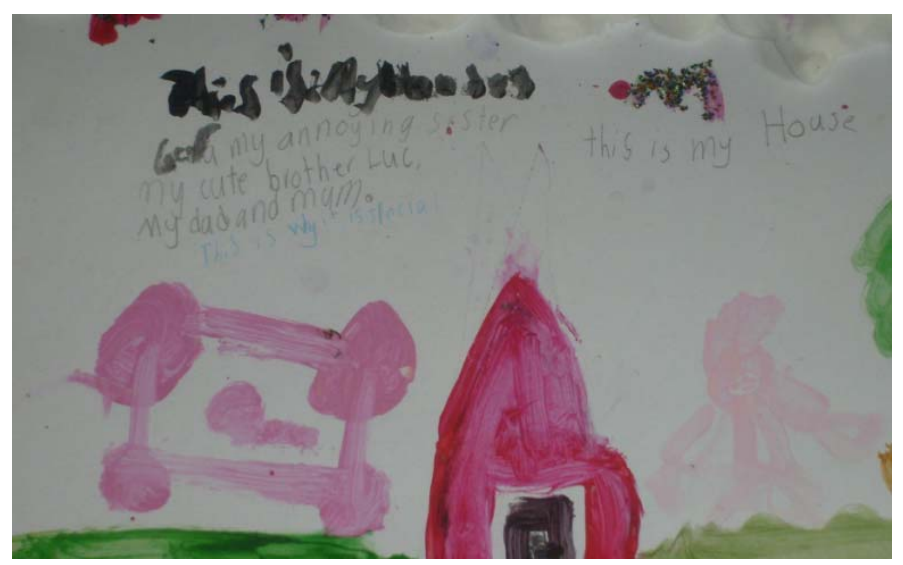

Figure 2

Another factor impacting on children's place attachments, evident in children's stories and interviews were activity affordances. Children often referred to their 'special place' in terms of what activities they could do there. These ranged from physically stimulating activities, such as "swimming", "ice-skating" and "playing at the park"; to sedentary activities, such as "playing computer games", "watching tv" and "eating”.

Time was another factor investigated in children's 'special place' stories and interviews. Time was considered in two ways: the frequency which children visited their 'special place'; and the duration of time the child had considered this place as a 'special place'. Most children described visiting their special place infrequently and had only considered it special for "the last year or two".

Positive feelings were the final factor seen to contribute to children's place attachments. Children reported feeling "happy", "excited" and "safe" in their 'special place' (Figure 3 below). For one child 'safe' represented familiarity as he explained in his interview "Coz it's like I know it really well, same as my bedroom but I know my loungeroom more. It's like I'm 
more familiar with it coz I know where all the stuff are". When questioned about their feelings towards places that weren't their 'special place' children's responses included: "still happy”, "annoyed”, “not excited”, “not fun” and "scared”.

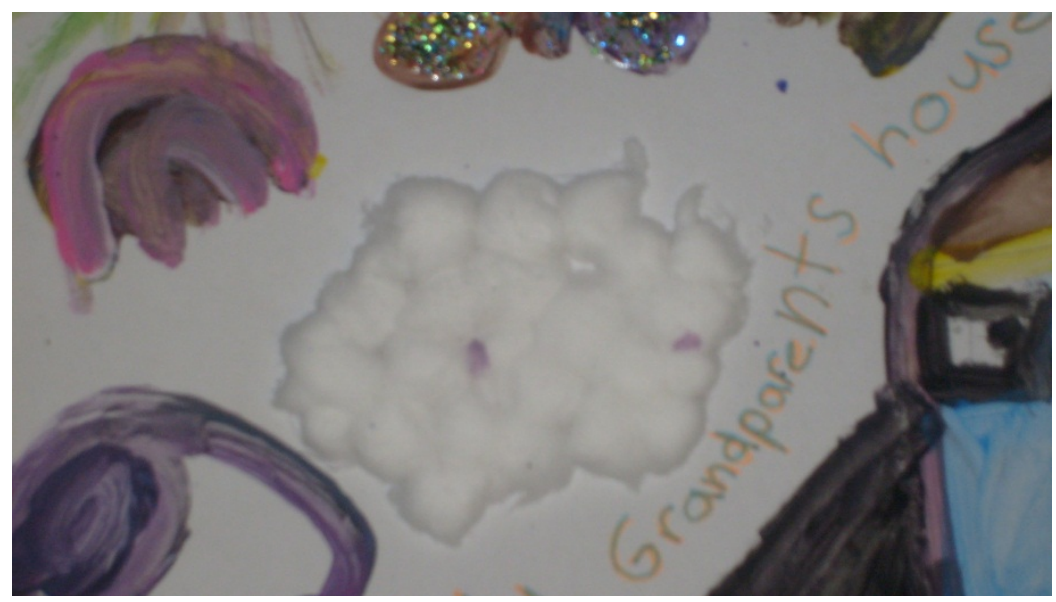

Figure 3

When elements from the quantitative content analysis were compared to categories developed in the open-coding analysis, the data were further refined into four key themes, thought to be indicative and influential in the formation of a child's place attachments. These themes were apparent in a majority of the children's 'special place' representations and included: national places, visited infrequently; outdoor places that in actuality are indoor ones; places dominated by human-made features; and places associated with positive feelings. The themes will be explored in further depth below.

\section{Interpretation:}

\section{"All of the places I have been to [in Cairns] are not really special places" so I've gone} National!

Previous studies into young children's place preferences have identified early childhood as a period where the local environment is explored and children's favourite places are homes, gardens and nearby streets; places where direct and repeated experiences occur, thus reinforcing a place attachment (Jack, 2010). The results of this study did not correlate with these research findings, with many children presenting their 'special place' as a national, holiday destination, visited infrequently.

Children's choices of national places over local ones may reflect what Gruenewald \& Smith (2008) define as 'placelessness', a concept expressing people's loss of locality because, rather than inhabiting places, they are merely residing in them. This is an alarming possibility, especially in today's globalised world, where travel has become increasingly easy. Presented with the novel sights and sounds of a globalised world, it remains possible that local environments no longer possess the qualities children require to form an attachment. Indeed, one of the interviewees, when questioned why he didn't choose a 'special place' in the local 
region explained "Well I'm trying to, but all of the places I have been to [in Cairns] are not really a special place” (Figure 4 below).

It is important to note, however, that the children included in this study sample are from middle to upper socioeconomic backgrounds. Global travel is a lived reality for these children; an opportunity that other children may not receive. Thus caution must be taken when considering the transferability of these results.

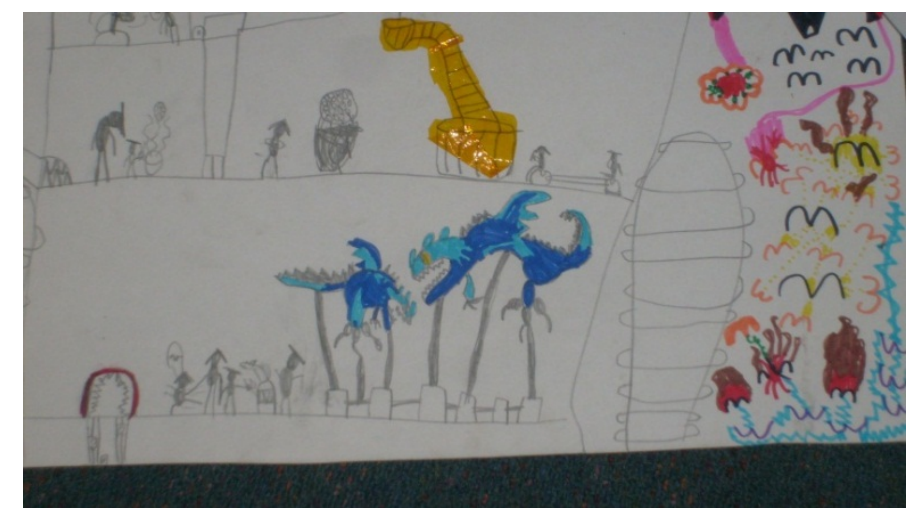

Figure 4

A second reason that may account for children choosing national, holiday destinations over places of everyday interactions could be the loss of a carefree childhood. LeFebvre (2005, cited in Kringen \& Nagel, 2006, p.47) states that "the concept of a carefree childhood with time for leisure play and free time is becoming less of a reality while hyper-scheduling, overbusyness and loss of family time is becoming more of a reality for many children". Holiday destinations, then, may provide children with the experiences of leisure and family time; both activities that appear to be diminishing in recent times.

A third explanation for the variance between previous studies findings and this one could be attributed to differences in conceptual understandings. When introducing the task of collaging a 'special place', the assumption was made that the children's definition of 'special place' would align with the researchers'. As a peer explained, 'special' could represent a variety of meanings depending on the person, including "out of the ordinary". There were no discussions pertaining to the meaning of 'special place' to avoid influencing the children's artworks. Thus, it remains a possibility that children represented a place not of attachment, as were the intentions of this study, but a 'special place' defined by uniqueness or novelty.

\section{“Things are seldom what they seem”: Outdoor Collages, but Indoor Foci}

Wilson's (1984) 'Biophillia Hypothesis' states that we as human beings, have an affinity, indeed a basic human need to form connections with the natural world and that it is during middle childhood (6-12 years) that this biological drive is strongest (White, 2004). Initial examination of children's collages appeared to support this hypothesis, with a majority of children depicting outdoor places, such as a house with its natural surroundings. However, story and interview data revealed that while the visuals presented outdoor places, children often described indoor activities.

Originally, it was considered that children drew the outside perspective of the house, rather than the indoors because of perceived artistic competence. In middle childhood there if often 
a decline in children's artistic expression due to a lack of confidence in their artistic abilities (Sorin, 2008). Evidence of this was provided in this study when a child, who had collaged a wonderful image of his loungeroom, transformed the television into a car because he had examined his peers' work and assumed he was doing the task 'wrong' (Figure 5 below). Upon making the change, however, he realised his mistake and started to cry, stating that his collage was "ruined" and "sucked".

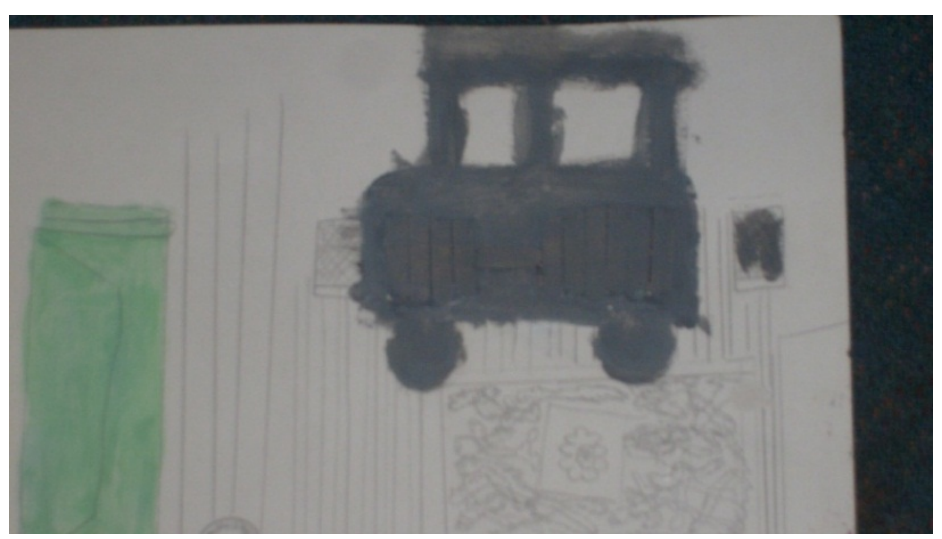

Figure 5

Artisitc competence, however, may not have been the only reason why children represented outdoor places but described indoor activities. Survey statistics reveal that " $94 \%$ of children want to spend more time out of the house” (Lester \& Maudsley, 2006, p.23). In changing times where parents work longer hours, children have limited time to interact in the outdoors. Parents today live in a 'protective discourse' where anxieties over their child's safety prevent children having the freedom to explore their local environments independently (Jack, 2010). Therefore children's outdoor representations but indoor foci could possibly be a sign from the children of their desire to spend more time in the outdoors.

\section{"If my DS goes down [at the camping spot] I can't do anything": Children's reliance on} human-made objects

In a survey conducted by the Children's Play Council (2002), a majority of the 500 children surveyed referred to their local parks and playgrounds as "boring” (Lester \& Maudsley, 2006). As a result of unattractive, unappealing outdoor environments, children are expressing an increased desire for television and video games (Freuder, 2006).

Even in this small-scale study, children's collages, stories and interviews made frequent mention of human-made technologies, particularly gaming consoles and televisions. For example, one child explained that his loungeroom was special to him because "it has powerpoints for my DS". Perhaps the biggest shock, however, was a young girl who depicted her family camping spot. When questioned about whether she preferred her camping spot alone or with others, she responded "with others because I feel like I got nothing to do and if my DS goes down I can't do anything coz I don't know what to do” (Figure 6). 


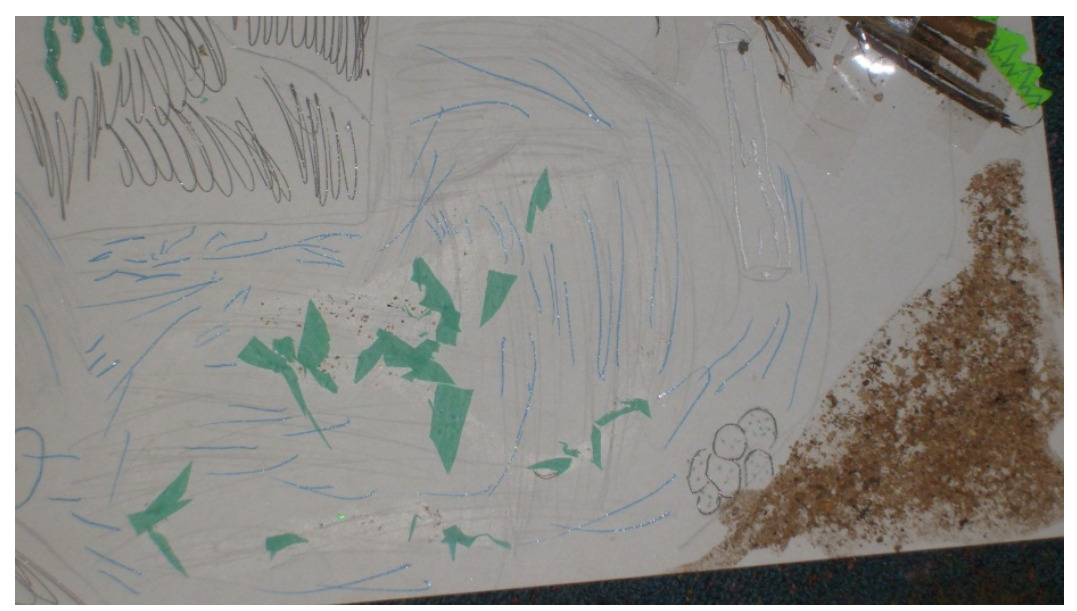

Figure 6

Findings like these communicate an urgent need to reconnect children with the wonders of the outdoors. As Pyle (1993) argues "It is through close and intimate contact with a particular patch of ground that [children] learn to respond to the earth... We need to recognise the humble places where the alchemy occurs...Everybody has a ditch, or ought to. For only the ditches - and the field, the woods, the ravines - can teach us to care enough (xviii-xix).

\section{Special Places are "safe": The positive feelings}

"Place attachment depends on developing clusters of positive cognitions linked to the meaning of specific places” (Jack, 2010, p.758). In this study it was found that the children's identified 'special places' did, in fact, evoke positive feelings. Children explained that their 'special place' made them feel "happy", "excited" and "safe”. Safe could be related to feelings to familiarity as a previous example highlighted, as well as to privacy. One of my child interviewees expressed how having a portable potty at the family camping spot increased her privacy and contributed to her feelings of being safe. Her excerpt states "it has a place where you can put a potty. But I don't like it. So it covers up everything so no one sees or knows that you're going there”.

Chawla (2007) states that, a child feels attached to a place when they feel happy when in their special place and distressed when leaving it. This appeared true with the children featured in this study, with one child stating they felt "scared" when they weren't in their special place because "they didn't know it as well" and another claiming he felt "annoyed, because I want to go to my special place". It appears then that the children who participated in this study were able to choose places to which they had formed attachments.

\section{Conclusion:}

In conclusion the findings from this study have revealed that for the children in this study, place attachments are shifting from natural, local places to human-made, national ones. Obtaining these findings was achieved through the use of the Arts as a research tool. Not only did the Arts provide an alternative representational tool for children, but the use of collage combined with storytelling assisted the researchers to more holistically interpret children's depictions. Collage, presented a fun and engaging way for children to share their ideas and thoughts; while storytelling allowed children to interpret their own visuals and share stories of their experiences in their 'special place/s'. 
This study has made apparent, at least in this sample of children, that "children are disappearing from the outdoors at a rate that would make them top of any conservationist's list of endangered species if they were any other member of the animal kingdom” (Gill, 2005, p.1). Children's disconnect with nature needs to be addressed and overcome to ensure that children are prepared to make informed decisions about the sort of future they wish to shape. The role of forming place attachments in doing so appears obvious, as children must learn to appreciate what is in their own backyard before they can learn to care for it. As Dighe (1993, cited in Graves, 1998, p.150) magnifies "One can hardly imagine a generation of persons with neither interest in, nor knowledge of the outdoors making responsible decisions regarding the environment.”

\section{Works Cited}

Alerby, E. (2000). A Way of Visualising Children's and Young People's Thoughts about the Environment: a study of drawings. Environmental Education Research, 6 (3), 205222.

Anning, A., \& Ring, K. (2004). Making Sense of Children's Drawings. Berkshire, England: Open University Press.

Barraza, L. (1999). Children's Drawings About the Environment. Environmental Education Research. 5 (1), 49-66.

Black, N.M. (2009). BLOOD MONEY. A grounded theory of Corporate Citizenship. Myanmar (Burma) as a Case in Point. Unpublished doctoral dissertation, University of Waikato.

Blizard, C. R., \& Schuster, R. M. (2007). Fostering Children's Connections to Natural Places through Cultural and Natural History Storytelling. Children, Youth and Environments, 17 (4), 171-206.

Borgers, N., Hox, J., \& Leeuw, E. (2000). Children as Respondents in Survey Research: Cognitive Development and Response Quality. Bulletin of Social Methodologies, 66, 60-75.

Butler-Kisber, L., \& Poldma, T. (2009). The power of visual approaches in qualitative inquiry: The use of collage making and concept mapping in experiential research. Proceedings of the EKSIG Conference: Experiential knowledge, method and methodology. London (June).

Chawla, L. (2007). Childhood Experiences Associated with Care for the Natural World: A Theoretical Framework for Empirical Results. Children, Youth and Environments, 17 (4), 144-170.

Ewert, A., Place, G., \& Sibthorp, J. (2005.) Early Life Outdoor Experience and an Individual's Environmental Attitudes. Leisure Sciences, 27 (3), 225-239. 
Freuder, T. (2006). Designing for the Future: Promoting Ecoliteracy in Children's Outdoor Play Environments. Unpublished doctoral dissertation, Virginia Polytechnic Institute and State University.

Gill, T. (2005). If you go down to the woods today. The Ecologist, October 2005.

Graves, N. (Eds.). (1998). Education and the Environment. London: World Education Fellowship.

Gruenewald, D., \& Smith. G. (Eds.). (2008). Place-Based Education in the Global Age: Local Diversity. New York, London: Taylor \& Francis Group.

Huss, E. \& Cwikel, J. (2005). Researching creations: Applying arts-based research to Bedouin women's drawings. International Journal of Qualitative Methods, 4(4), Article 4. Retrieved $1^{\text {st }}$ August, 2011, from http:// www.ualberta.ca/ iiqm/backissues/4_4/pdf/huss.pdf

Jack, G. (2010). Place Matters: The Significance of Place Attachments for Children's Wellbeing. British Journal of Social Work, 40, 755-771.

Kellert, S.R., Heerwagen, J., \& Mador, M. (2008). Biophilic Design: the theory, science and practice of bringing buildings to life. Hoboken, N.J.: Wiley.

Klassen, M. (2010). Connectedness to Nature: Comparing Rural and Urban Youths' Relationships with Nature. Unpublished doctoral dissertation, University of Manitoba, Manitoba.

Kringen, E., \& Nagel, A. (2006). The Effects of Over-Scheduled Children: Perspectives of Childcare Worker. Journal of Student Research, 5, 47-56.

Lester, S., \& Maudsley, M. (2006). Play, naturally: A review of children's natural play. London: National Children's Bureau.

Louv, R. (2005). Last Child in the Woods: Saving Our Children from Nature Deficit Disorder. Chapel Hill, NC: Algonquin Books.

Louv, R. (2008.) Last Child in the Woods. Chapel Hill, NC: Algonquin Books.

Patton, M.Q. (2002). Qualitative Research and Evaluation Methods ( $3^{\text {rd }}$ ed.). California, London, New Delhi: Sage Publications.

Pyle, R.M. (1993) .The Thunder Tree: Lessons from and Urban Wildland. Boston: Houghton Mifflin.

Rose, G. (2007). Visual Methodologies: An Introduction to the Interpretation of Visual Materials ( $2^{\text {nd }}$ ed.). Los Angeles, London, New Delhi, Singapore \& Washington DC: Sage Publications.

Sobel, D. (1996). Beyond Ecophobia: Reclaiming the heart in nature education. Great Barrington, MA: The Orion Society. 
Sorin, R. (2004). Understanding children's feelings - Emotional literacy in early childhood. Research in Practice Series. Canberra: Early Childhood Australia. ISBN: 0975193546.

Sorin, R. (2008). The Development of Children's Art. Lecture Notes for ED3094 - The Arts in Early Childhood. James Cook University.

Sorin, R., \& Gordon, I. (2009). Frogs in the Drain - Children's Perceptions of the Tropical Landscape. eTropic - electronic journal of studies in the tropics.

Steadman, R. (2003). Is It Really Just a Social Construction?: The Contribution of the Physical Environment to Sense of Place. Society and Natural Resources, 6 (8), 671685.

Switzer, S. (2006). A “Triangulated Data” Approach to Assessing Academic English of English Language Learners. In Proceedings of the Pan Pacific association of Applied Linguistics. Kangwon University, Chuncheon, South Korea.

United Nations Educational, Scientific and Cultural Organisation (2009). UNESCO Review of Contexts and Structures for Education for Sustainable Development 2009. Paris, France: Arjen Wals.

Westoby, M. (1993). Biodiversity in Australia compared to other continents in R.E. Ricklefs and D. Schluter (eds). Historical and Geographic Determinants of Community Diversity. Chicago: University of Chicago Press.

White, R. (2004). Young Children's Relationship with Nature: its importance to children's development and the earth's future .Kansas City, MO: White Hutchinson Leisure and Learning Group. Retrieved December 12, 2009 from the World Wide Web: http://www.whitehutchinsyon.com/children/articles/nature.shtml.

Wilson, E. (1984). Biophilia. Cambridge, MA: Harvard University Press.

Wilson, R. (1997). The wonders of nature: Honoring children's ways of knowing. Early Childhood News, 9 (2), 6-9, 16-19.

Wright, S. (2008). Young Children's meaning making through drawing and 'telling': Analogies to filmic textual features. Australian Journal of Early Childhood. 32 (4), 37-48. 